\title{
Estudio de la retina y el nervio óptico tras el uso de células madre en enfermedades neurodegenerativas en un modelo animal
}

\section{Evaluation of the retina and optic nerve after the use of stem cells for neurodegenerative disorders in an animal model}

\author{
Romana García-Gil1*, Anselmo Feliciano-Sanchez ${ }^{1}$, Laura Cubas-Nuñez ${ }^{2}$, Jessica Castillo-Villalba², \\ Jorge Fuentes-Maestre ${ }^{3}$, Mariana Fil ${ }^{3}$, Jose M. García-Verdugo ${ }^{3,4}$ y Sara Gil-Perotin ${ }^{5 *}$
}

${ }^{1}$ Servicio de Oftalmología, Unidad Retina Médica y Quirúrgica, Hospital Universitario y Politécnico La Fe; ${ }^{2}$ Neuroinmunologia y Regeneración Neuronal, Instituto de Investigación Sanitaria La Fe; ${ }^{3}$ Departamento de Biología Celular y Parasitología, Universidad de Valencia; ${ }^{4}$ Departamento de Neurobiología comparada, Universidad de Valencia; ${ }^{5}$ Servicio de Neurología, Unidad Mixta de Esclerosis Múltiple y Neurorregeneración, Hospital Universitario y Politécnico La Fe. Valencia, España

\section{Resumen}

Objetivo: Estudiar la respuesta neuroprotectora y neurorregeneradora de las células mesenquimales adultas (aMSC) sobre las células ganglionares de la retina (CGR) y el nervio óptico (NO) en un modelo animal de esclerosis múltiple, como la encefalitis autoinmune experimental (EAE). Métodos: Se estudiaron los cambios que ocurrieron en la retina y el NO, se analizó el efecto de la inyección endovenosa de células mesenquimales. Se estudiaron tres grupos: sanos (control), enfermos (EAE), enfermos en tratamiento con aMSC (EAE-MSC). Los animales fueron monitorizados y seguidos mediante escalas de discapacidad motora. Las retinas y nervios ópticos se procesaron para: microscopia óptica, inmunofluorescencia y microscopia electrónica. Resultados: Los resultados demostraron que tras la administración de aMSC intravenosas se producía una menor pérdida de CGR, el promedio de CGR en el grupo EAE fue de $0.0891 \mu \mathrm{m}$, frente $0.1166 \mu \mathrm{m}$ del grupo EAE-MSC, con un valor de $p$ estadísticamente significativo $(p=0.01)$. Se producía una reducción de la respuesta celular inflamatoria en el NO (7.99 células/ $\mu m^{2}$ frente 3.69 células $/ \mu m^{2} ; p<0.0001$ ), disminución de la pérdida de mielina (el daño axonal global se reduciría al $54 \%$ frente al $88 \%$ ) y menor destrucción axonal $\left(0.16745\right.$ axones $/ \mu m^{2}$ frente 0.3598 axones $\left./ \mu m^{2} ; p=0.0251\right)$. Conclusiones: En este trabajo, encontramos tras la administración de aMSC, una menor pérdida de CGR, disminución de la pérdida de mielina y menor grado de inflamación en el NO; sin embargo, sería aconsejable ampliar la metodología para poder asegurar un efecto inmunosupresor y neuroprotector en este modelo.

Palabras clave: Neuritis óptica. Encefalitis autoinmune experimental. Células mesenquimales. Neuroprotección. Inmunomodulación.

\section{Abstract}

Objective: To study the neuroprotective and neuroregenerative response of adult mesenchymal cells (aMSCs) on retinal ganglion cells (RGC) and optic nerve (ON) in an animal model of multiple sclerosis (MS) like experimental autoimmune encephalitis (EAE). Methods: We studied the changes that occurred in the retina and ON, analyzing the effect of an intravenous injection of aMSCs.

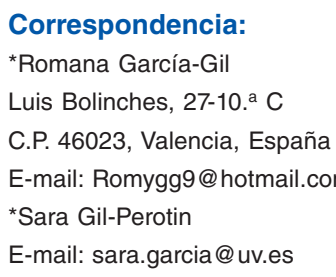


Three groups were studied: healthy (control), sick (EAE) and sick treated with aMSCs (EAE-MSC). The animals were monitored using motor disability scales. The retinas and ONs were studied with optical microscopy, immunofluorescence and electron microscopy. Results: The results showed that after administration of intravenous aMSCs there was a lower loss of RGC, the average of RGC in the EAE group was of $0.0891 \mu \mathrm{m}$ compared to $0.166 \mu \mathrm{m}$ in the EAE-MSC group, with a statistically significant $p$ value $(p=0.01)$. There was a reduction in the inflammatory cell response of the ON $\left(7.99\right.$ cells/ $\mu m^{2} v s .3 .69$ cells/ $/ \mu m^{2}, p<$ 0.0001 ), a decrease of myelin loss (overall axonal damage was of $54 \%$ compared to $88 \%$ ) and less axonal destruction (0.16745 axons $/ \mu m^{2}$ vs. 0.3598 axons $/ \mu m^{2}(p=0.0251)$. Conclusions: In this study, we found that after the administration of aMSCs there was a lower loss of RGC, a decrease of myelin loss and a lower degree of inflammation in the ON. However, it would be advisable to expand the methodology to ensure an immunosuppressive and neuroprotective effect in this model.

Key words: Optic neuritis. Experimental autoimmune encephalitis. Mesenchymal cells. Neuroprotection. Immunomodulation.

\section{Introducción}

La esclerosis múltiple (EM) se considera una de las causas más comunes de discapacidad neurológica en adultos jóvenes. Consiste en una enfermedad crónica e inflamatoria del sistema nervioso central (SNC), caracterizada por desmielinización axonal, gliosis y degeneración neuronal. Una hipótesis patógena relaciona la EM con respuestas disinmunes, con la participación de autoanticuerpos, complemento y mediadores innatos de respuesta inmunitaria'. Los fármacos inmunosupresores se consideran terapias modificadoras de la enfermedad, ya que pueden reducir la discapacidad, la frecuencia de recaída, la gravedad y la duración de los síntomas.

Desafortunadamente, las terapias modificadoras de la enfermedad no son curativas y, en ocasiones, no evitan el cambio a cursos progresivos 0 , una vez alcanzados, la progresión de la discapacidad².

Las terapias celulares representan una nueva frontera en el tratamiento de enfermedades neurológicas. En este contexto, las células madre mesenquimales adultas (aMSC) han demostrado su potencial terapéutico en varios modelos de enfermedades. Debido a que las aMSC se comportan de forma heterogénea según el tejido de origen y las condiciones de cultivo. La International Society for Cell Therapy en el año 2006, estableció unas pautas para la caracterización de acuerdo a tres criterios $\left.^{3}: 1\right)$ crecimiento en adherencia a las superficies plásticas utilizadas para su cultivo; 2) expresión de las moléculas de superficie (CD73, CD90 y CD105), y la ausencia de marcadores de monocitos y macrófagos (CD11b y CD14), marcador leucocitario (CD45), marcador de células $B$ (CD19 o CD79a), marcador de progenitores hematopoyéticos y marcadores de células endoteliales (CD34), y HLA-DR; y 3) capacidad de diferenciación in vitro hacia osteoblastos, adipocitos y condroblastos.

El beneficio ejercido por las aMSC se ha asociado con la capacidad de diferenciarse en varios linajes celulares, segregar factores solubles cruciales para la proliferación y la supervivencia celular ${ }^{4}$, modular la respuesta inmune ${ }^{5}$ y migrar al sitio de la lesión ${ }^{6}$. Dado que el daño tisular derivado de la inflamación es un proceso clave desencadenado en respuesta a una lesión y enfermedad, las aMSC podrían convertirse en un tratamiento para cualquier daño tisular u orgánico asociado con una actividad inflamatoria intensa ${ }^{5}$.

Se han diseñado múltiples modelos de EM en investigación experimental para lograr una mejor comprensión de la patogénesis de la enfermedad y los mecanismos de progresión. La encefalomielitis (encefalitis autoinmune experimental, EAE) es un modelo animal de EM basado en la inmunización activa que reproduce clínicamente la lesión inflamatoria que se produce en la EM. La neuritis óptica, una inflamación del nervio óptico (NO) y la lesión progresiva de la médula espinal se han descrito en ratones de la cepa B6/C57 tras la inmunización con un fragmento de la glicoproteína mielínica del oligodendrocito (MOG) que comprende de 35 a 55 residuos de aminoácidos $\left(\mathrm{MOG}_{35-55}\right)$. Esta lesión incluye la desmielinización con daño axonal posterior y la pérdida neuronal que también afecta al ojo, en particular a las células ganglionares de la retina (CGR) ${ }^{7}$. De hecho, se ha demostrado que la gravedad del curso de la EAE se correlaciona con los signos de desmielinización e inflamación en el $\mathrm{NO}^{8}$.

\section{Objetivo}

Estudiar la respuesta neuroprotectora y neurorregeneradora de las aMSC sobre las CGR y el NO en un modelo animal de EM.

\section{Material y métodos}

\section{Los animales}

Se utilizaron 24 ratones hembra B6/C57 de 10 semanas de edad. Los animales se dividieron en tres grupos: grupo control (10 animales), grupo EAE (7 
animales) y grupo EAE-MSC (animales con EAE tratados con aMSC, administradas por vía intravenosa) (7 animales). Los posibles efectos de la inyección de aMSC en animales control se descartó durante el proceso de desarrollo y optimización del modelo animal. Estos animales fueron utilizados para la experimentación animal según las directrices éticas de experimentación animal. Los animales con EAE se inyectaron con $\mathrm{MOG}_{35-55}(200 \mu \mathrm{g}$ de péptido/animal en $200 \mu \mathrm{l}$ intraperitoneal $)^{9}$, se monitorizaron cada $24-48$ h y se les evaluó la discapacidad motora. Al grupo EAE-MSC se le inyectó $1 \times 10^{6} \mathrm{aMSC}^{10}$ junto con una proteína verde fluorescente (GFP) por vía intravenosa en la vena de la cola. Consideramos el inicio de la enfermedad como la aparición de debilidad de la cola distal y/o leve movimiento irregular. Cuando los animales cumplieron con los criterios de punto final (cuando el animal es incapaz de conseguir alimento o agua), se sacrificaron mediante eutanasia. Posteriormente, se perfundieron a través del ventrículo izquierdo del corazón con 50 cc de solución salina estéril ( $\mathrm{NaCl}$ al $0.9 \%)$, seguido de $150 \mathrm{cc}$ de paraformaldehído (PFA) al $4 \%$ o glutaraldehído al 2\% de PFA-2.5\% solución. Más tarde, los globos oculares y los NO se extrajeron y, posteriormente, se fijaron en el mismo fijador durante $24 \mathrm{~h}$. Luego, se lavaron con solución salina tamponada con fosfato (PBS) $0.1 \mathrm{M}$. Finalmente, las muestras se mantuvieron a $4{ }^{\circ} \mathrm{C}$ en PBS $0.1 \mathrm{M}$ con azida de sodio al $0.05 \%$ para evitar la contaminación bacteriana y por hongos.

\section{Crecimiento, caracterización y transfección de células madre mesenquimales adultas con proteína verde fluorescente}

Todas las muestras fueron recogidas como un producto de cirugía plástica de pacientes sometidos de forma electiva a procedimientos de lipoaspirados quirúrgicos en la Clínica Cervera Sebastián (Valencia, España). Se entregó un formulario de consentimiento informado a los pacientes para que fuera firmado y almacenado en la base de datos CELULIFE, tras recibir información del estudio. El uso de muestras de tejido adiposo fue aprobado por el Comité de Ética correspondiente (CAEC, Comité Autonómico de Ensayos Clínicos, Valencia, España). Los participantes no recibieron compensación financiera. El estudio siguió en todo momento las leyes y regulaciones vigentes, incluyendo los principios éticos derivados de la Declaración de Helsinki, la política internacional sobre la realización de estudios clínicos recogida en las International Guidelines for Ethical Review of Epidemiological Studies (Council for the
International Organizations of Medical Sciencies-CIOMS-Ginebra, 2009) y las Recomendaciones sobre Buena Práctica Clínica.

El aislamiento de las células madre derivadas de tejido adiposo se llevó a cabo utilizando un método mecánico y enzimático. La mezcla de digestión estaba compuesta por Dulbecco's Phosphate-Buffered Saline (DPBS) pH 7.5 (Life technologies Cat $n$-10010056) con $1 \mathrm{mg} / \mathrm{ml}$ de colagenasa tipo I (Gibco Cat № 17100-017) y el mismo volumen de tejido adiposo lipoaspirado. El tejido era digerido durante 30 minutos a $37^{\circ} \mathrm{C}$ en condiciones de agitación, y más tarde se filtró para separar tejido no digerido y centrifugado a $500 \mathrm{~g}$ durante 10 minutos a temperatura ambiente. El sobrenadante (adipocitos flotantes) se separó del sedimento (fracción de células madre derivadas de tejido adiposo). Las células se resuspendieron en un tampón de lisis de eritrocitos (BD Cat \# 555900), se incubaron a temperatura ambiente durante 10 minutos y se centrifugó a $500 \mathrm{~g}$ durante 10 minutos a $20^{\circ} \mathrm{C}$. Finalmente, las células fueron resuspendidas y expandidas en medio de cultivo Dulbecco's Modified Eagle Medium (DMEM) con bajo contenido de glucosa (Gibco 31885023), suplementado con $10 \%$ de suero humano y $1 \%(\mathrm{v} / \mathrm{v})$ de penicilina/estreptomicina $(10,000 \mathrm{U} / \mathrm{ml}$ de penicilina, $10,000 \mu \mathrm{g} / \mathrm{ml}$ de estreptomicina, Gibco Life Technologies, n. ${ }^{\circ 15140-122) . ~}$ Las células madre derivadas del tejido adiposo se cultivaron a $37{ }^{\circ} \mathrm{C}$ en una atmósfera de aire con $5 \%$ de $\mathrm{CO}_{2}$ con cambios medios cada 3 días. Cuando las células alcanzaron en el matraz aproximadamente el $80 \%$ de confluencia, el subcultivo (pase) se realizó mediante tripsinización, se contó y se volvió a colocar en una caja de cultivo celular T75 tratadas con polilisina para crecimiento celular en mono capa a una densidad de 5,000 células $/ \mathrm{cm}^{2}$. Para la tripsinización, el medio de cultivo se aspiró y el matraz se lavó usando PBS. Luego, se desechó la solución y se añadió tripsina $6 \mathrm{ml} /$ matraz y se dejó durante 5 minutos. La tripsina se neutralizó utilizando la misma cantidad de medio completo. La suspensión celular se centrifugó (500 g durante $7 \mathrm{mi}-$ nutos) y se aspiró su sobrenadante. El sedimento se resuspendió en medio completo y las células se contaron utilizando la prueba de exclusión de azul tripán (hemocitómetro). En el cuarto paso, se transfectaron por electroporación con un plásmido que expresaba GPF. El vector de expresión se construyó mediante la inserción en el vector vacío obtenido comercialmente (Invitrogen) pCEP4 el gen de la GPF. De este modo, el plásmido se introdujo en la concentración adecuada, y 24 horas después fue posible determinar la eficacia del proceso mediante detección por fluorescencia. Esta 
placa se incubó durante 3 días a $37^{\circ} \mathrm{C}$ con $5 \%$ de $\mathrm{CO}_{2}$. Las células se caracterizaron completamente como aMSC por inmunofenotipo con citometría de flujo ${ }^{11}$.

\section{Procesado del nervio óptico y la retina para el estudio histológico}

Se obtuvieron secciones longitudinales de globo ocular (400 $\mu \mathrm{m}$ de espesor) con un vibrátomo (Vibratomo Leica 1000mM Biosystems). Las secciones del NO se seleccionaron a su salida del globo ocular y se sometieron a dos procedimientos diferentes: 1) crioprotección en sacarosa al $30 \%$, congelación rápida con nitrógeno líquido y secciones histológicas de $10 \mu \mathrm{m}$ de espesor con un criostato (CM1900, Leica, Heidelberg, Alemania), las secciones se tiñeron con hematoxilina-eosina y azul de toluidina; 2) inclusión en resina epoxi y secciones de $1.5 \mu \mathrm{m}$-semifinas con un ultramicrotomo (Ultracut, Leica ultracut-MZ6). La glía residente y reactiva se detectó en secciones congeladas de $10 \mu \mathrm{m}$ mediante inmunomarcaje con anticuerpo policlonal de conejo anti-GFAP (proteína ácida fibrilar glial) (\#12692777, Fisher Scientific, Hampton, New Hampshire, EE.UU.) diluido 1:200, se incubaron diluidas en tampón de bloqueo (5\% normal goat serum (NGS), $5 \%$ caseína en PBS) durante toda la noche a $4 \stackrel{\circ}{\circ}$. Se lavaron las muestra en PB $0.1 \mathrm{M}$, y se realizó la incubación del anticuerpo secundario (cabra anti-conejo alexa 555, \#A21428, Fisher Scientific) diluido $1: 500$ en $5 \%$ (NGS) en PBS durante 1 hora a temperatura ambiente, conjugado con fluorescencia. A continuación se lavaron las muestras en PB $0.1 \mathrm{M}$ y se montaron con medio acuoso (Fluorsave ${ }^{\circledR}$ ).

\section{AnÁlisis CUANTITATIVOS DE MUESTRAS HISTOLÓGICAS E INMUNOHISTOQUÍMICAS}

En las secciones teñidas con hematoxilina-eosina/ azul-toluidina, se realizaron 246 fotos, se seleccionaron 3 secciones por muestra y se realizaron 3-4 fotos por sección, dependiendo de la presencia del NO o la retina, 0 de la presencia de ambos. Finalmente, se tomaron y analizaron 80 fotos del grupo de control, 84 fotos del grupo EAE y 82 fotos del grupo EAE-MSC. Los números de CGR por unidad de longitud se midieron en una distancia promedio de $300 \mu \mathrm{m}$ a ambos lados de la entrada del NO, un área de referencia con menos variabilidad anatómica para permitir recuentos reproducibles en muestras distintas. Los CGR se contaron manualmente.

Para estudiar la inflamación endógena, se detectaron células gliales residentes y reactivas con anticuerpos anti-GFAP. El total de células positivas a GFAP por micrón se contó en 3 secciones/animal por grupo y se analizaron las diferencias entre ellas.

\section{AnÁlisis CUANTITATIVOS BAJO MICROSCOPÍA ELECTRÓNICA: G-RATIO Y DENSIDAD AXONAL}

Para los estudios cuantitativos de microscopia electrónica de transmisión (MET), los NO se seccionaron transversalmente. De todas las secciones semifinas, se seleccionaron aquellas con NO y retina, y luego se obtuvieron secciones ultrafinas, de 70-80 nm, se incluyó en resina (Leica EM-UC6) para completar el análisis morfológico con un estudio ultraestructural bajo el microscopio electrónico (microscopia electrónica de transmisión FEl-Tecnai-Spirit-G2, Oregon, EE.UU.).

La G-ratio se obtuvo como la relación entre el diámetro axonal interno (excluyendo la mielina) y el diámetro exterior total (incluida la vaina de mielina). En las secciones ultrafinas del NO, se estudiaron más de 100 axones por grupo y se clasificaron como normales (proporción G:0.74$0.84)^{12}$, axones remielinizantes (proporción G:0.85-0.94) y axones con daño severo a la mielina (proporción G:0.951). Se obtuvieron 103 micrografías con microscopía electrónica de transmisión (48 fotos del grupo de control, 25 fotos del grupo EAE y 30 fotos del grupo EAE-MSC). La densidad axonal se calculó como el número de axones por micrómetro cuadrado en cuatro secciones por animal. Esta medida se obtuvo como la media promedio de dos observadores independientes cegados (RGG, LCN).

\section{Análisis estadístico}

Debido a que nuestro tamaño de muestra excluyó las pruebas paramétricas, realizamos la prueba $U$ de Mann-Whitney para estudiar la significación estadística entre grupos experimentales. Las diferencias entre los grupos analizados se consideraron significativas si el valor de $p<0.05$. Para comparaciones de más de dos grupos, utilizamos la prueba de Kruskal-Wallis.

\section{Resultados}

\section{Los animales tratados con células madre mesenquimales adultas presentaban un periodo libre de enfermedad mayor que los animales no tratados}

Los animales con EAE experimentaron los primeros signos clínicos desde el día 7 hasta el día 19 después de la inmunización. Estos síntomas consistían en déficits motores secundarios a la lesión de la médula espinal y 


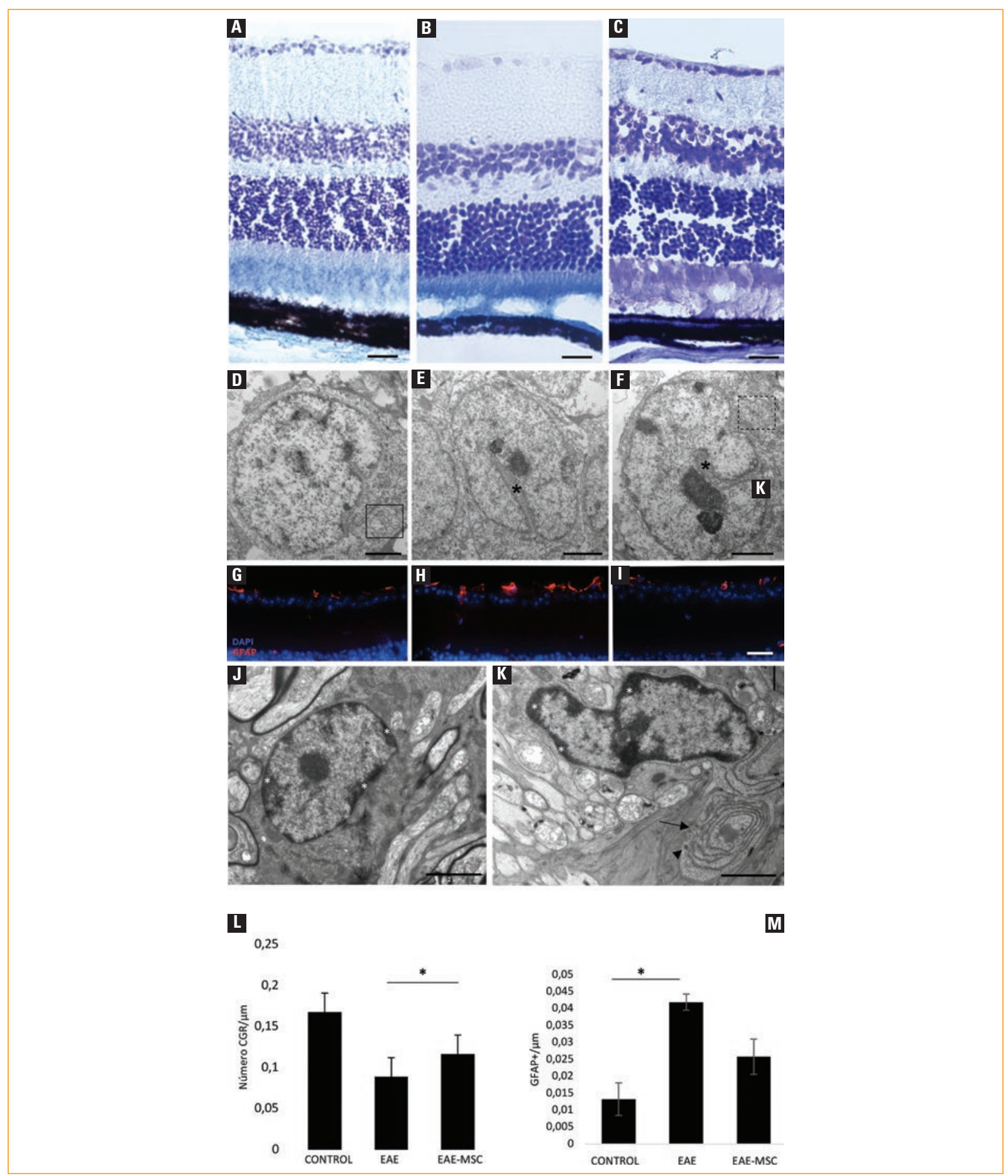

Figura 1. Estudio comparativo histológico y ultraestructural de la retina. A-C: secciones de criostato de la retina teñidas con azul de toluidina en el grupo control (A), grupo de encefalitis autoinmune experimental (EAE) (B) y grupo de EAE en tratamiento con células madre mesenquimales adultas (EAE-MSC) (C) (escala $10 \mu \mathrm{m})$. D-F: micrografías, secciones ultrafinas, estudio ultraestructural de las células ganglionares de retina (CGR) en el grupo control (D), donde muestran un núcleo grande y redondeado, cromatina dispersa, abundante retículo endoplásmico y microtúbulos característicos (recuadro), grupo EAE (E) y grupo EAE-MSC (F). La morfología de las CGR está alterada en el grupo tratado con EAE, y el grupo MSC muestra núcleos invaginados (asterisco) y citoesqueleto más desorganizado (recuadro discontinuo) (escala $2 \mu \mathrm{m}$ ). G-I: la expresión de proteína ácida fibrilar glial (GFAP) (rojo) en la capa de CGR en el grupo control (G), grupo EAE (H) y grupo EAE-MSC (I) (escala $20 \mu \mathrm{m}$ ). J,K: células de microglía, se caracterizan por un núcleo irregular, con condensación de cromatina en la periferia (asteriscos), con grandes cisternas alargadas (flecha) y lisosomas secundarios (punta de flecha) (escala $2 \mu \mathrm{m}$ ). L: evaluación cuantitativa de CGR por $\mu \mathrm{m}$ en los tres grupos estudiados. M: evaluación cuantitativa del número de células gliales (GFAP+) en la retina por $\mu \mathrm{m}$. 
eran progresivos, ya que nuestro modelo reproducía un curso crónico ${ }^{9}$. El inicio consistió en un déficit focal con pérdida del tono muscular de la cola, seguido de una paresia progresiva ascendente que condujo a criterios de punto final en distintos puntos temporales (los animales fueron llevados a eutanasia por consideraciones éticas). El curso clínico fue variable, con una esperanza de vida promedio de 57 días (rango 30-70). Aunque hubo un retraso en el inicio de la enfermedad en el grupo EAE-MSC en comparación con el grupo EAE (10 vs.13 días), los valores de $p$ no fueron estadísticamente significativos ( $p$ $=0.07$ ). En un momento dado (45 días a partir de la inmunización), los animales en el grupo EAE alcanzaron una discapacidad máxima promedio de 3.5 puntos, se evidenció la instauración de la enfermedad, con una afectación motora grave, parálisis de las cuatro extremidades, que dificultó al animal la obtención de alimentos y agua, mientras que los animales del grupo tratado con aMSC presentaron una puntuación máxima de 2.5 puntos, la enfermedad se manifestó con la parálisis de dos extremidades (las dos traseras o una delantera y una trasera). Todos los animales cumplieron los criterios de punto final y fueron sacrificados para su procesamiento.

\section{La inmunización con encefalitis autoinmune experimental condujo a cambios morfológicos y disminuyó el número de células ganglionares de la retina con un efecto favorecedor tras la administración de células madre mesenquimales adultas}

Las aMSC se transfectaron con un plásmido que expresaba GFP para poder detectar aMSC injertadas mediante inmunofluorescencia. No pudimos encontrar aMSC como células GFP+ en nuestras muestras de la retina o el NO, sin embargo, observamos cambios en la viabilidad neuronal, la mielinización y la inflamación local, como lo describimos con más detalle.

En la EAE y en los grupos tratados, la morfología retiniana a bajo aumento no difirió de la de los ratones control (Figs. 1 A-C). Sin embargo, el análisis con MET mostró que los CGR en el grupo control eran células grandes con núcleos redondeados y un núcleo central con cromatina dispersa, abundante retículo endoplásmico rugoso y microtúbulos (Fig. 1 D). En contraste, en los grupos de EAE y tratados, el citosol de las CGR fue más oscuro, con núcleos más pequeños y con grandes invaginaciones, muy evidentes, que alcanzaron hasta el centro del núcleo (Fig. 1 E) y que perdieron su esfericidad adquiriendo una forma arriñonada
(Fig. 1 F). Presentaron un citoesqueleto desorganizado que sugirió que las CGR estaban dañadas (Figs.1 E y F). Las células gliales adyacentes caracterizadas por citosol ligero, filamentos intermedios y núcleos invaginados se observaron con mayor frecuencia en los grupos de EAE y tratados en comparación con el control. Las células microgliales con citosol oscuro, forma invaginada, cisternas largas y lisosomas fueron más abundantes en las regiones estudiadas de ratones inmunizados (Figs. $1 \mathrm{~J}$ y K). Ambos tipos de células también se observaron con inmunohistoquímica contra GFAP, una proteína de los filamentos intermedios presentes en los astrocitos (Figs. $1 \mathrm{~L}$ y M).

Las CGR se alteraron morfológicamente en ratones inmunizados, pero para evaluar si los cambios morfológicos estaban relacionados con la pérdida de células, cuantificamos el número de CGR por unidad de longitud en secciones de retina longitudinales en todos los grupos. En línea con nuestros datos anteriores, el número de CGR en el grupo de control mostró un promedio de $0.1678 \mathrm{CGR} / \mu \mathrm{m}$. El grupo EAE y el grupo tratado con aMSC mostraron una disminución significativa en el número de CGR con valores de $0.0891 \mathrm{CGR} / \mu \mathrm{m}(p=0.000035)$ y 0.116 ( $p=0.0002) \mathrm{CGR} / \mu \mathrm{m}$, respectivamente, en comparación con los ratones de control. Cuando se compararon los números de CGR entre EAE y el grupo tratado con aMSC, las diferencias también fueron significativas $(p=0.01)$ (Fig. $1 \mathrm{~L}$ ).

La inmunohistoquímica contra GFAP mostró un aumento en las células GFAP+ en el grupo EAE $(0.0419$ células GFAP+/ $/ \mu \mathrm{m}$ ) y en el grupo tratado ( 0.0322 células $\mathrm{GFAP}+/ \mu \mathrm{m}$ ) en comparación con el grupo control ( 0.0132 células GFAP+/ $\mu \mathrm{m})$ (Fig. $1 \mathrm{M})$. Estos resultados mostraron un aumento significativo en las células GFAP+ en animales inmunizados en comparación con los ratones de control $(p=0.038)$ y una respuesta parcial al tratamiento con aMSC que, sin embargo, no alcanzó la significación estadística $(p=0.068)$.

\section{La inflamación endógena y la desmielinización en el nervio óptico de ratones inmunizados se rescató parcialmente con células madre mesenquimales adultas intravenosas}

La observación de la morfología de las secciones longitudinales del NO con tinción histológica a bajo aumento mostró que en el grupo de EAE el nervio adoptó contornos irregulares con regiones estrechas demarcadas, que se correspondían con áreas de 


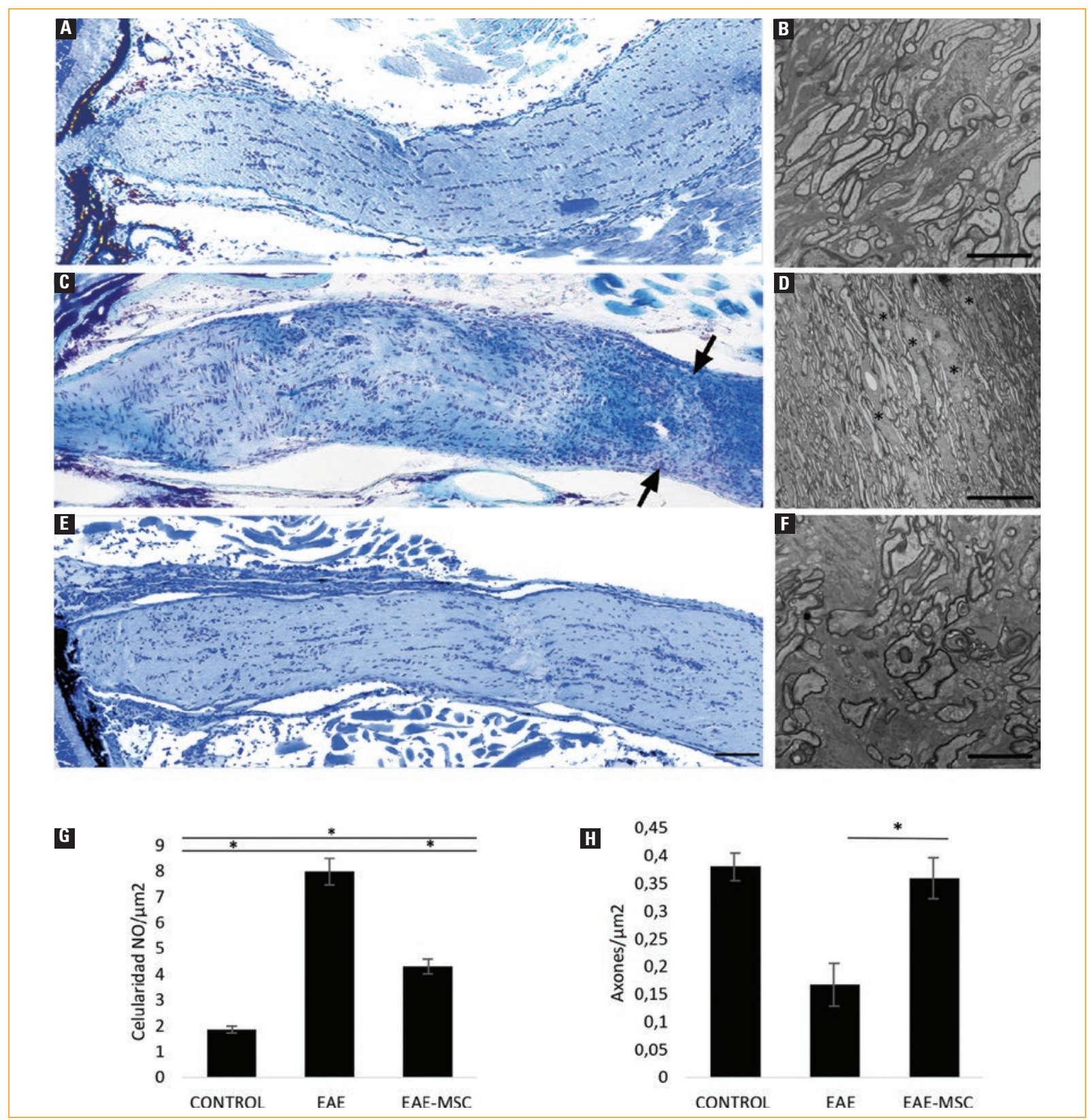

Figura 2. Estudio comparativo histológico y ultraestructural del nervio óptico (NO). A,C,E: secciones de criostato del NO teñidas con azul de toluidina en el grupo control (A), grupo de encefalitis autoinmune experimental (EAE) (C) y grupo de EAE en tratamiento con células madre mesenquimales adultas (EAE-MSC) (E); flechas negras: contornos irregulares focales, con incremento de la densidad celular, escala $200 \mu \mathrm{m}$. B,D,F: estudio ultraestructural de los axones del NO en el grupo control (B), grupo EAE (D) y grupo EAE-MSC (F); asterisco: astrocitos que rellenan los espacios existentes por la falta de mielina con sus cuerpos celulares y expansiones. Estos astrocitos reactivos son células grandes, ocasionalmente multinucleadas, con abundantes filamentos intermedios distribuidos en el citoplasma. Los núcleos son grandes, ligeramente irregulares, con cromatina laxa, escala $5 \mu \mathrm{m}$ (B), escala $20 \mu \mathrm{m}$ (D) y escala $5 \mu \mathrm{m}$ (F). G: densidad celular en el NO por $\mu \mathrm{m}^{2}$. Diferencias significativas entre todos los grupos $(p<0.05)$. H: densidad axonal (números de axones por $\mu \mathrm{m}^{2}$ ). Diferencias estadísticamente significativas a favor del grupo EAE-MSC $(p<0.05)$.

mayor densidad celular (flechas Fig. 2 C), en comparación con la ausencia de estrechamientos del $\mathrm{NO}$ en los ratones del grupo control (Fig. 2 A).
Estos datos se confirmaron en las imágenes a MET, los axones en el NO de los ratones inmunizados mostraron signos de degeneración, como un citosol oscuro con 


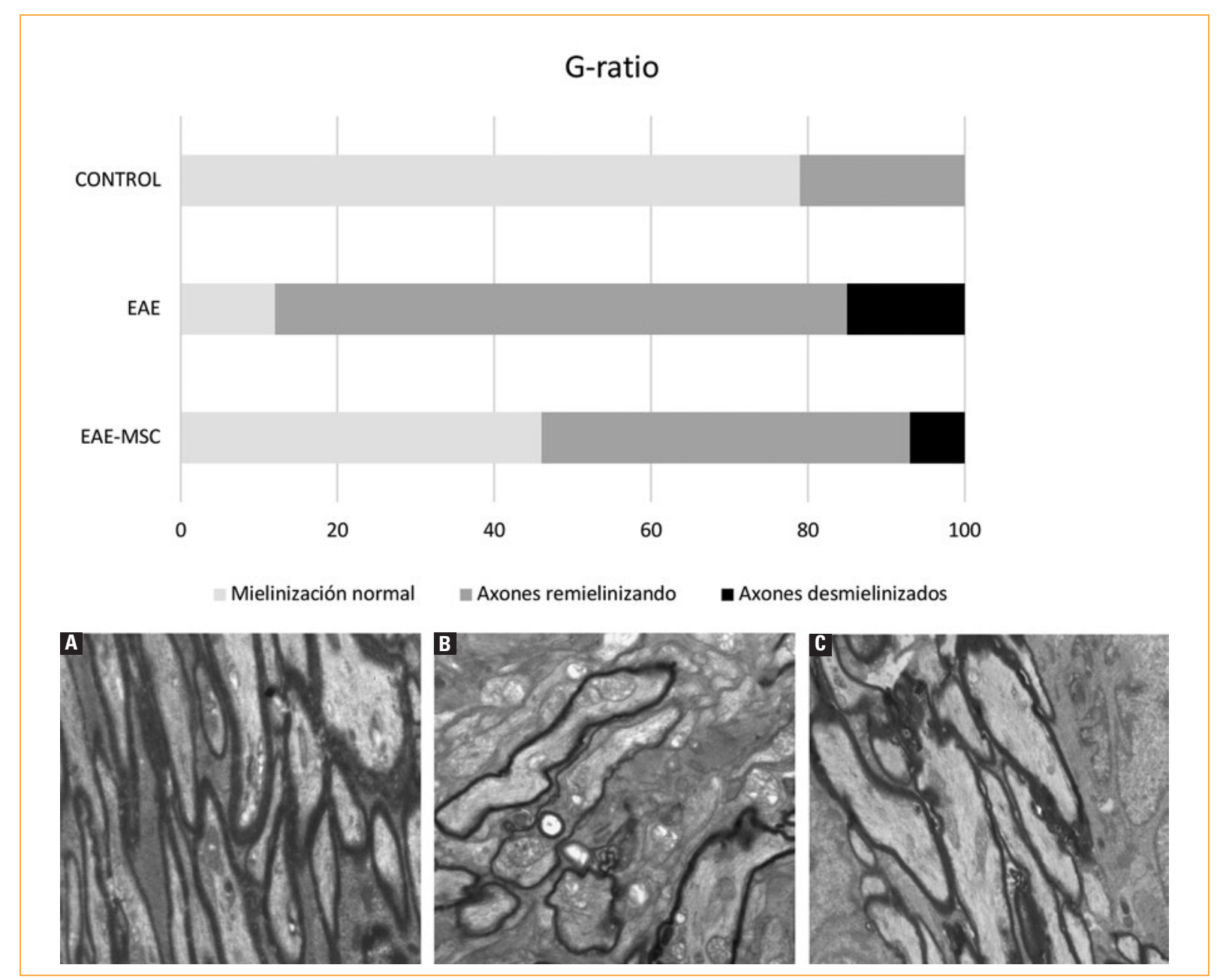

Figura 3. Estudio del grado de mielinización. G-ratio. Los ratones EAE-MSC muestran una desmielinización que se recuperó tras el tratamiento con aMSC. A-C: estudio ultraestructural axonal. A: control: axones con mielinizacion homogénea: mielinización normal. B: EAE: axones desorganizados con gran desmielinizacion. C: EAE-MSC: axones desorganizados en proceso de remielinización, escala $5 \mu \mathrm{m}$.

una red de microtúbulos interrumpida en el axonema y cuerpos de esferoides de mielina, en lugar de vainas mielínicas concéntricas regulares, como se observó en los ratones de control (Fig. $2 \mathrm{D}$ ), además se observaron abundantes astrocitos reactivos en el espacio intercelular entre los axones mielinizados dañados (asterisco en $2 \mathrm{D}$ ).

El tratamiento con aMSC disminuyó los signos degenerativos en la mielina y los axones, mostró menos infiltrados de células gliales en el NO dañado y dio lugar a un estado intermedio entre los ratones control y tratados. Para determinar estos cambios cuantitativamente, obtuvimos secciones transversales de NO y, al teñir con azul de toluidina, se contaron las células por unidad de área $\left(\mu \mathrm{m}^{2}\right)$ (Fig. $\left.2 \mathrm{G}\right)$. En el grupo control, el promedio de células por unidad de área fue de 1.86 células $/ \mu^{2}$, mientras que en el grupo de EAE, 7.99 células $/ \mu m^{2}$. El tratamiento con aMSC dio como resultado 3.69 células/ $\mu \mathrm{m}^{2}$. Los estudios estadísticos mostraron una diferencia significativa entre los tres grupos $(p<0.0001)$. Posteriormente, las diferencias específicas entre la celularidad media de los sujetos en ambos grupos (EAE y EAE-MSC) se compararon mediante la prueba $U$ de Mann Whitney, que también resultó estadísticamente significativa $(p=$ 0.0143). Para calcular la densidad axonal (Fig. $2 \mathrm{H}$ ), contamos el número de axones por unidad de área. Mientras que en el grupo de control obtuvimos una densidad axonal de 0.38049 axones $/ \mu \mathrm{m}^{2}$, en el grupo EAE, el valor obtenido fue de 0.16745 axones/ $/ \mathrm{m}^{2}$, y esta disminución fue significativa $(p=0.0003)$. La comparación de la densidad axonal entre EAE y el grupo tratado con 
administración aMSC (0.3598 axones/ $\left.\mu \mathrm{m}^{2}\right)$ fue estadísticamente significativa a favor del grupo tratado $(\mathrm{p}=0.0251)$.

Los resultados del G-ratio en los ratones EAE-MSC muestran una desmielinización que se recuperó tras el tratamiento con aMSC (Fig. 3). En el grupo de control, el $79 \%$ de los axones estaban normalmente mielinizados, el $21 \%$ de los axones ingresaron en el grupo de los axones remielinizados y ninguno de los axones estudiados fue desmielinizado. En contraste, en el grupo de EAE, encontramos un $12 \%$ de los axones normales, un $73 \%$ de remielinización de los axones y un 15\% de los axones con daño agudo de la mielina. Los ratones EAE-MSC exhibieron el $46 \%$ de los axones envueltos con mielina normal, el $47 \%$ en proceso de remielinización y el $7 \%$ de los axones desmielinizados. Cabe señalar que, si consideramos el porcentaje de axones que habían sufrido algún daño (agrupando los procesos de remielinización y desmielinización) con valores de G por encima de 0.84 , el total de axones alterados fue del $88 \%$ en el grupo de EAE comparado con el $54 \%$ en el grupo EAE-MSC.

\section{Discusión}

En este trabajo hemos estudiado el posible efecto de las aMSC, hemos evaluado que la infusión intravenosa de aMSC podría mejorar el daño inflamatorio, desmielinizante y neurodegenerativo tanto en la retina como en el NO, mientras que, desafortunadamente, el efecto clínico no fue suficiente para detener la progresión de la enfermedad.

Por otro lado, estudios publicados sobre diferentes modelos de daño axonal (isquemia transitoria de la retina ${ }^{13}$ 0 axotomía $\mathrm{NO}^{14}$ describieron que la interrupción de los axones de las CGR causó degeneración axonal retrógrada que provocó la muerte de las $\mathrm{CGR}^{15}$. En nuestro trabajo observamos una pérdida significativa de CGR en ratones EAE en comparación con el grupo control, lo que podría ser el resultado del daño axonal documentado en el NO y la degeneración Walleriana. Otra posibilidad sería que, como la inflamación del NO y el daño estructural parecían ser más relevantes, la muerte de los CGR fuera provocada por el efecto tóxico local de la microglía, que aumentó en los grupos de EAE y EAE-MSC, como se informó en otros modelos de inflamación ocular ${ }^{16}$. El tratamiento con aMSC mejoró la inflamación en el NO, disminuyó la pérdida de CGR, pero no se observó ningún efecto en el rescate de las CGR ya perdidas, esto podría deberse a un mejor acceso de las aMSC al NO a través de la barrera hematoencefálica ${ }^{17} \mathrm{o}$ a un efecto retardado de la disminución de la inflamación en el NO debido a aMSC en la degeneración de Walleriana en la retina.
Las aMSC representan una población de células madre multipotenciales que cuando se administran por vía intravenosa tienen la capacidad de migrar e injertarse en lugares donde se producen daños en los tejidos e inflamación. Describimos que las aMSC administradas por vía intravenosa tenían la capacidad de disminuir los infiltrados inflamatorios y reducir la pérdida de mielina y el daño axonal. Este efecto no se relacionó con el injerto de aMSC, porque no pudimos encontrar aMSC fluorescentes verdes en nuestras muestras. Esto podría deberse a varias causas, incluido el secuestro en otros órganos (hígado, pulmones), el rechazo inmunológico y/o la muerte de células por apoptosis una vez en el SNC. Según los estudios realizados a este respecto, las aMSC administradas por la vena de la cola en ratones inicialmente se acumulan en los pulmones y pasan gradualmente al hígado, bazo, riñón y médula ósea en las primeras 48 horas $^{18,19}$. Rochefort, et al. encontró acumulación en pulmón del $50-60 \%$ de las aMSC 1 hora después de la inyección, con una disminución subsiguiente hasta aproximadamente el $30 \% 3$ horas después de la inyección ${ }^{20}$. En humanos, el mismo grupo inyectó aMSC por vía intravenosa y también mostró una alta captación pulmonar en 30 minutos $^{21}$. Numerosos estudios han demostrado la baja inmunogenicidad de aMSC que, al no expresar MHC-II, evita el reconocimiento por parte de las células dendríticas y los linfocitos T. Sin embargo, aunque se han considerado células que no producen rechazo cuando las células se exponen a un medio inflamatorio caracterizado por la presencia de niveles elevados de interferón- $\gamma^{22}$ comienzan a expresar el HLA-DR (MHC-II), y por lo tanto se convierten en células inmunogénicas, y son susceptibles de rechazo. Sin embargo, nuestros estudios y otros demuestran que, además de la baja eficiencia del injerto del SNC, hay un efecto neuroprotector después de la administración de aMSC. Este efecto, denominado «by-stander», se ha descrito en estudios en infarto de miocardio después de la infusión de aMSC, donde se observó una mejoría clínica y funcional, pero no fue posible identificar células injertadas o células diferenciadas de los miocardiocitos ${ }^{23,24}$. Las aMSC se caracterizan por una alta capacidad de comunicación paracrina basada en la liberación de pequeñas vesículas o exosomas $^{25}$. A los exosomas se les ha atribuido el efecto de las aMSC a distancia. Podría ser que la disminución de la respuesta inflamatoria observada en nuestro estudio pudiera deberse a la liberación a distancia de exosomas con acción neurotrófica e inmunomoduladora adicional. Sin embargo, los mecanismos exactos todavía no se entienden completamente. 
Dentro de las limitaciones de este estudio se encuentra el tamaño muestral reducido, y el seguimiento de la enfermedad con escalas de discapacidad motora por falta de medios por nuestra parte; el seguimiento con técnicas como la tomografía de coherencia óptica ${ }^{26}$ aplicada en animales, para visualización de estructuras retinianas y del NO, in vivo hubiera permitido hacer un mejor control de la enfermedad. Sería interesante en un futuro ampliar este estudio mejorando las limitaciones encontradas.

La aportación más interesante de este trabajo es su enfoque oftalmológico al estudiar la muerte de las CGR, así como las técnicas sofisticadas empleadas para ello como es la microscopía electrónica.

Finalmente, quisimos enfatizar que, tras la administración de aMSC, encontramos una menor pérdida de CGR, disminución de la pérdida de mielina y menor grado de inflamación en el NO; sin embargo, sería aconsejable ampliar la metodología para poder asegurar un efecto inmunosupresor y neuroprotector en este modelo. Dado que el daño tisular derivado de la inflamación es un proceso clave que se desencadena en respuesta a una lesión y enfermedad, las aMSC podrían convertirse en tratamiento de cualquier daño tisular u orgánico asociado con una actividad inflamatoria intensa.

\section{Conclusiones}

En este trabajo encontramos, tras la administración de aMSC, una menor pérdida de CGR, disminución de la pérdida de mielina y menor grado de inflamación en el NO; sin embargo, sería aconsejable ampliar la metodología para poder asegurar un efecto inmunosupresor y neuroprotector en este modelo.

\section{Conflicto de intereses}

Los autores declaran no tener conflicto de intereses.

\section{Responsabilidades éticas}

Protección de personas y animales. Los autores declaran que los procedimientos seguidos se conformaron a las normas éticas del comité de experimentación humana responsable y de acuerdo con la Asociación Médica Mundial y la Declaración de Helsinki.

Confidencialidad de los datos. Los autores declaran que han seguido los protocolos de su centro de trabajo sobre la publicación de datos de pacientes.

Derecho a la privacidad y consentimiento informado. Los autores han obtenido el consentimiento informado de los pacientes y/o sujetos referidos en el artículo. Este documento obra en poder del autor de correspondencia.

\section{Bibliografía}

1. Noseworthy $\mathrm{JH}$. Progress in determining the causes and treatment of multiple sclerosis. Nature. 2000;399:A40-7.

2. Dolati S, Babaloo Z, Jadidi-Niaragh F, Ayromlou H, Sadreddini S, Yousefi M. Multiple sclerosis: Therapeutic applications of advancing drug delivery systems. Biomed Pharmacother. 2017;86:343-53

3. Dominici M, Le Blanc K, Mueller I, Marini FC, Krause DS, Deans RJ, et al. Minimal criteria for defining multipotent mesenchymal stromal cells. The International Society for Cellular Therapy position statement. Cytotherapy. 2006;8(4):315-7

4. Galderisi U, Giordano A. The Gap Between the Physiological and Therapeutic Roles of Mesenchymal Stem Cells. Med Res Rev. 2014;34(5):1100-26.

5. De Miguel MP, Fuentes-Julián S, Blazquez-Martínez A, Pascual CY, Aller MA, Arias J, et al. Immunosuppressive properties of mesenchymal stem cells: advances and applications. Curr Mol Med. 2012;12(5):574-91.

6. Yagi H, Soto-gutierrez A, Parekkadan B, Kitagawa Y, Tompkins G, Kobayashi $\mathrm{N}$, et al. Mesenchymal stem cells: mechanisms of immunomodulation and homing. October. 2010;19(6):667-79.

7. Shindler KS, Guan Y, Ventura E, Benett J, Rostami A. Retinal Ganglion Cell Loss Induced By Acute Optic Neuritis in Relapsing Model of Multiple Sclerosis. Mult Scleros. 2006;12(5):526-32.

8. Horstmann L, Schmid H, Heinen AP, Kurschus FC, Dick HB, Joachim SC. Inflammatory demyelination induces glia alterations and ganglion cell loss in the retina of an experimental autoimmune encephalomyelitis model. $J$ Neuroinflammation. 2013;10:1-12.

9. Feliciano-Sanchez A, García-Gil R, Cubas-Nuñez L, Castillo-Villalba J, Fuentes-Maestre J, Fil M, et al. Development and optimisation of an animal model for the study of ganglion cells in degenerative diseases of the retina and optic nerve. Arch la Soc Española Oftalmol. 2019;94(6):263-72.

10. Pierini M, Dozza B, Lucarelli E, Tazzari PL, Ricci F, Remondini D, et al. Efficient isolation and enrichment of mesenchymal stem cells from bone marrow. Cytotherapy. 2012;14(6):686-93.

11. García-Contreras M, Vera-Donoso CD, Hernández-Andreu JM, García-Verdugo JM, Oltra E. Therapeutic potential of human Adipose-Derived Stem Cells (ADSCs) from cancer patients: A pilot study. PLoS One. 2014:9(11):e113288.

12. Chomiak T, Hu B. What is the optimal value of the g-ratio for myelinated fibers in the rat CNS? A theoretical approach. PLoS One. 2009;4(11):e7754.

13. Sellés-Navarro I, Villegas-Perez MP, Salvador-Silva M, Ruiz-Gómez JM, Vidal-Sanz M. Retinal ganglion cell death after different transient periods of pressure-induced ischemia and survival intervals: A quantitative in vivo study. Investig Ophthalmol Vis Sci. 1996;37(10):2002-14.

14. Borsello T, Mottier V, Castagné V, Clarke PGH. Ultrastructure of retinal ganglion cell death after axotomy in chick embryos. J Comp Neurol. 2002;453(4):361-71

15. Galindo-Romero C, Avilés-Trigueros M, Jiménez-López M, Valiente-Soriano FJ, Salinas-Navarro M, Nadal-Nicolás F, et al. Axotomy-induced retinal ganglion cell death in adult mice: Quantitative and topographic time course analyses. Exp Eye Res. 2011;92(5):377-87.

16. Guan $Y$, Shindler KS, Tabuena $P$, Rostami AM. Retinal ganglion cell damage induced by spontaneous autoimmune optic neuritis in MOG-specific TCR transgenic mice. J Neuroimmunol. 2006;178(1-2):40-8.

17. Hu P, Pollard J, Hunt N, Chan-Ling T. Microvascular and cellular responses in the retina of rats with acute experimental allergic encephalomyelitis (EAE). Brain Pathol. 1998;8(3):487-98.

18. Daldrup-Link HE, Rudelius M, Metz S, Piontek G, Pichler B, Settles M, et al. Cell tracking with gadophrin-2: a bifunctional contrast agent for MR imaging, optical imaging, and fluorescence microscopy. Eur J Nucl Med Mol Imaging. 2004;31(9):1312-21.

19. Gao J, Dennis JE, Muzic RF, Lundberg M, Caplan Al. The dynamic in vivo distribution of bone marrow-derived mesenchymal stem cells after infusion. Cells Tissues Organs. 2001;169(1):12-20.

20. Rochefort GY, Vaudin P, Bonnet N, Pages J-C, Domenech J, Charbord P, et al. Influence of hypoxia on the domiciliation of mesenchymal stem cells after infusion into rats: possibilities of targeting pulmonary artery remodeling via cells therapies? Respir Res. 2005;6:125.

21. Kang WJ, Kang H-J, Kim H-S, Chung J-K, Lee MC, Lee DS. Tissue distribution of 18F-FDG-labeled peripheral hematopoietic stem cells after intracoronary administration in patients with myocardial infarction. J Nucl Med. 2006;47(8):1295-301.

22. Ryan JM, Barry F, Murphy JM, Mahon BP. Interferon- $\gamma$ does not break, but promotes the immunosuppressive capacity of adult human mesenchymal stem cells. Clin Exp Immunol. 2007;149(2):353-63.

23. Mazhari R, Hare JM. Mechanisms of action of mesenchymal stem cells in cardiac repair: potential influences on the cardiac stem cell niche. Nat Clin Pract Cardiovasc Med. 2007;4 Suppl 1:S21-6.

24. Ankrum JA, Faii Ong J, Karp JM. Mesenchymal stem cells: immune evasive, not immune privileged. Nat Biotechnol. 2014;32(3):252-60.

25. Yu B, Zhang X, Li X. Exosomes derived from mesenchymal stem cells. Int J Mol Sci. 2014;15(3):4142-57

26. Fischer MD, Huber G, Beck SC, Tanimoto N, Muehlfriedel R, Fahl E, et al. Noninvasive, in vivo assessment of mouse retinal structure using optical coherence tomography. PLoS One. 2009;4(10):e7507. 